\title{
RESEARCH ON DETERMINING THE NUTRITIONAL REQUIREMENTS OF VARIOUS POTATO VARIETIES AT SOLFARM SRL, COVASNA COUNTY
}

\author{
Iringo Deak $^{1, *}$, Mircea Mihalache ${ }^{1}$ \\ ${ }^{1}$ University of Agronomic Sciences and Veterinary Medicine of Bucharest, 59 Marasti Blvd, \\ District 1, Bucharest, Romania
}

Current Trends in

Natural Sciences

\begin{abstract}
Potato cultivation is mainly influenced by the type of fertilisers used, the dosage of mineral or organic fertilisers applied based on the soil nutrient supply and texture of the soil. The potato's particularities in growing stolons and tubers in the soil, the superficial root system, reltively smaller when compared to the above-ground part, make the plant's soil condition requirements different from other crops. The purpose of these experiments was to determine the nutrient content in the soil, in order to accurately determine the macro- and micro-element requirements, decided before starting the cultivation, as they are highly important in order to obtain a good yield. In order to monitor the soil nutrient supply, soil samples were taken at a depth of 0-20 and 20-40 cm for ten different varieties, i.e. Arizona, Esmee, Riviera, Red Lady, Carrera, Jelly, Red Fantasy, Levantina, Bellarosa and Luna Rosa, and based on them the ph values, the humus, nitrogen, phosphorus, potassium and mobile form ( $\mathrm{Cu}, \mathrm{Fe}, \mathrm{Mn}, \mathrm{Zn})$ content were established. Soil analysis is extremely important before starting the cultivation, because it helps farmers determine whether the type of soil is suitable for the plants to be grown and to determine an adequate fertilisation plan.
\end{abstract}

Keywords: nutritive elements, potato cultivation, soil analysis.

\section{INTRODUCTION}

The potato (Solanum tuberosum L.) is an extremely appealing agricultural crop, as it combines a great potential yield with a highly valuable nutritional. Nonetheless, while countries with intensive agriculture, such as the USA, France, and Germany, may reach average yields of potatoes over $45 \mathrm{t}$ ha, the average yields of most other countries are considerably lower, leading to an average yield of $20 \mathrm{t}$ ha around the world. Potatoes are a good source of energy, minerals, proteins, fats and vitamins (Ekin, 2011; Drewnowski and Rehm, 2013; King and Slavin, 2013). Furthermore, potatoes are not just an important source of food (Andre et al., 2014), they are used more and more as raw material for industrial products (Izmirlioglu and Demirci, 2015; Jagatee et al., 2015). Therefore, unlike most other crops, potatoes can be used in a wide range of applications, making their cultivation appealing to farmers. 
The potato's particularities in growing stolons and tubers in the soil, the superficial root system, relatively smaller when compared to the above-ground part, make the plant's soil condition requirements different from other crops. From an agricultural and phytotechnical perspective, the potato is a plant that grows on light, well structured and fertile sandy-argillaceous, argillaceous sandy, and argillaceous soils (even on sandy soils for early potato varieties), with well-balanced temperature, air and water conditions in the cool moist regions, where cereals are not successful.

The potato is within the scope of modern sustainable or ecological agriculture, due to its adequacy to optimal crop rotation structures of irregular duration, and as a result of its biological particularities, the potato is an almost ideal predecessor to spring barley or alfalfa and clover crops (Roman, 2012).

As regards the potato's soil reaction requirements resulting from the specialised literature, the optimal reaction for the potato falls within a wide range (5.2-7.2), without a significant influence on tuber production. The potato crop makes good use of the calcareous amendments to highly acidic soils, but only 3-4 years after their application, because potatoes grown on calcar-amended soils become sensitive to "Streptomyces scabies", being more acid-tolerant. As a row crop, the potato makes very good use of the direct effect of manure fertilisation, because in addition to the highly economical yield increase, it has a material contribution to maintaining and improving the physical and chemical properties of the soil, particularly the structure, $\mathrm{pH}$, and fertility. The potato is included in the group of plants with high nutritional requirements, because of its yield, as well as its poorly developed root system. Potato fertilisation must be conducted so that the climate and soil differences encourage nutrient uptake according to the rhythm and nutritional requirements per vegetative phase, for continual accumulation (Roman, 2012).

To accurately determine the macro- and micro-element requirements, we must first determine the soil's macro- and micro-element supply for the optimal dosage of mineral and organic fertilisers.

Maintaining soil fertility is one of the most important agronomical practices that must be adopted in potato cultivation, crop rotation being an alternate method available to potato farmers to maintain and improve soil fertility in addition to the use of organic and anorganic fertilisers (Agajie et al., 2007; LeMonte et al., 2009).

The high requirement of soil nutrients for a good tuber quality requires high quantities of organic matter and nitrogen intake (Nesbitt \& Adl, 2014).

\section{MATERIALS AND METHODS}

The research was carried out at SC SOLFARM SRL, located in Sfantu Gheorghe, where the type of soil is argic Faeoziom, in the Cernisoil class.

For laboratory analysis, soil samples were taken at a depth of 0-20 and 20-40 cm for ten different varieties, i.e. Arizona, Esmee, Riviera, Red Lady, Carrera, Jelly, Red Fantasy, Levantina, Bellarosa and Luna Rosa, semi-early varieties, with medium soil and water requirements, with medium-high disease and pest resistance.

The soil samples were analysed using the Bucharest ICPA (the National Research and Development Institute for Soil Science, Agrochemistry and Environment) methodology, as follows: determining the $\mathrm{pH}$ in a 1:2,5 aqueous solution; determining the humus content by wet oxidation; determining the nitrogen content $(\mathrm{Nt})$ using the Kjeldahl method; the phosphorus content $\left(\mathrm{P}_{\mathrm{AL}}\right)$ was determined by ammonium acetate-lactate extraction; the potassium content by ammonium acetate-lactate extraction. 


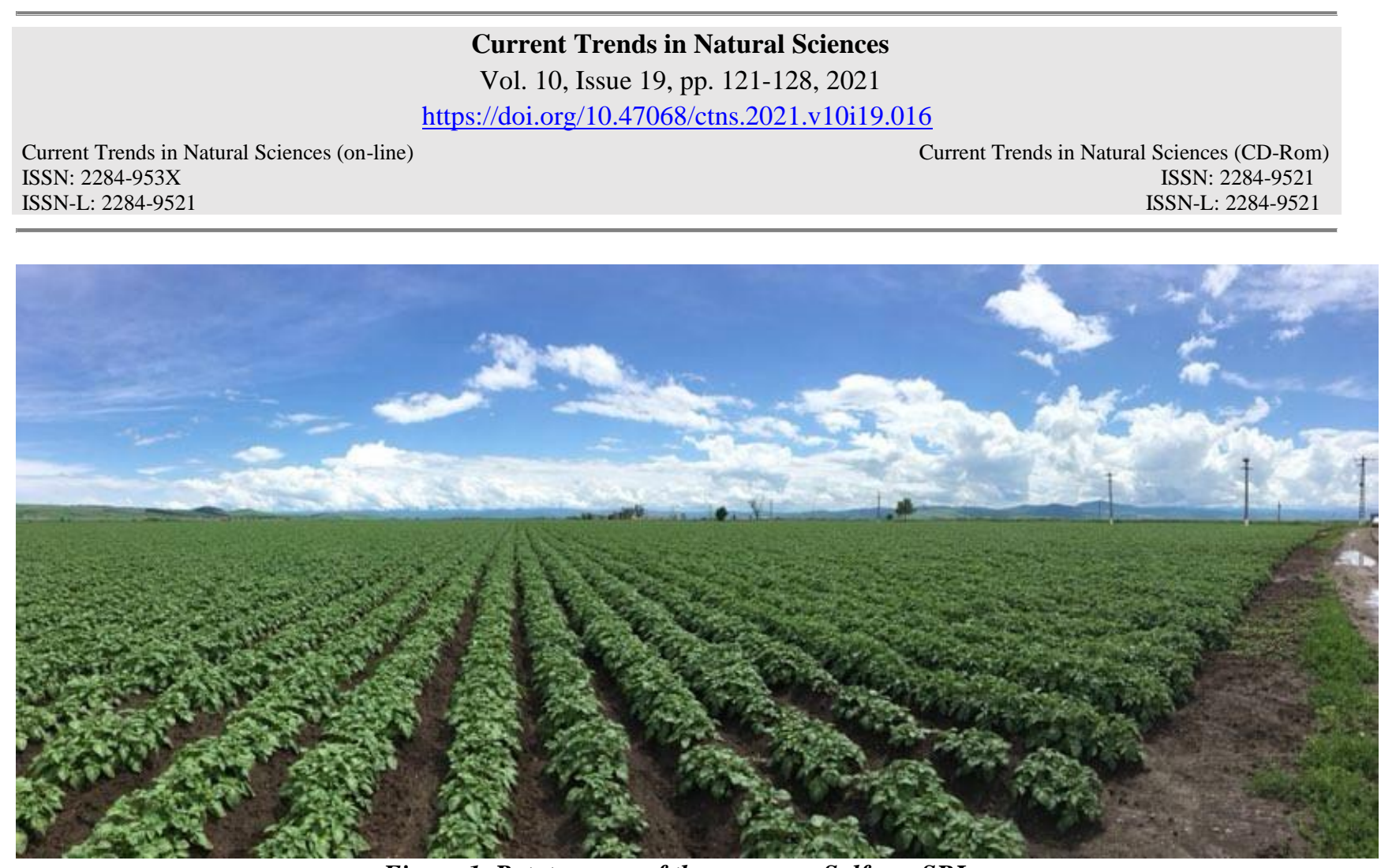

Figure 1. Potato crops of the company Solfarm SRL

\section{RESULTS AND DISCUSSIONS}

Table 1. Results for soil samples taken at SC.SOLFARM SRL.

\begin{tabular}{|c|c|c|c|c|c|c|}
\hline \multirow{3}{*}{ Identification } & \multirow[b]{2}{*}{ Depth } & \multicolumn{5}{|c|}{ Tests performed } \\
\hline & & \multirow{2}{*}{$\frac{\mathbf{p H}}{\mathrm{pH} \text { units }}$} & \multirow{2}{*}{$\begin{array}{c}\text { Humus } \\
\% \\
\end{array}$} & \multirow{2}{*}{$\begin{array}{c}\mathrm{Nt} \\
\%\end{array}$} & $\mathbf{P}_{\mathrm{AL}}$ & $\mathbf{K}_{\mathrm{AL}}$ \\
\hline & $\mathrm{cm}$ & & & & \multicolumn{2}{|c|}{$\mathrm{mg} / \mathrm{kg}$} \\
\hline \multirow{2}{*}{ S1 Arizona } & $0-20$ & 6.04 & 3.14 & 0.180 & 52 & 294 \\
\hline & $20-40$ & 6.14 & 3.08 & 0.185 & 65 & 206 \\
\hline \multirow{2}{*}{ S2 Esmee } & $0-20$ & 6.02 & 3.32 & 0.195 & 86 & 206 \\
\hline & $20-40$ & 6.09 & 3.26 & 0.189 & 58 & 200 \\
\hline \multirow{2}{*}{ S3 Riviera } & $0-20$ & 5.64 & 3.02 & 0.168 & 74 & 206 \\
\hline & $20-40$ & 5.54 & 2.96 & 0.168 & 63 & 235 \\
\hline \multirow{2}{*}{ S4 Red Lady } & $0-20$ & 5.49 & 3.20 & 0.182 & 81 & 210 \\
\hline & $20-40$ & 5.78 & 3.20 & 0.187 & 83 & 265 \\
\hline \multirow{2}{*}{ S5 Carrera } & $0-20$ & 5.44 & 3.26 & 0.189 & 81 & 247 \\
\hline & $20-40$ & 5.56 & 3.26 & 0.203 & 86 & 243 \\
\hline \multirow{2}{*}{ S6 Jelly } & $0-20$ & 5.57 & 3.02 & 0.174 & 55 & 139 \\
\hline & $20-40$ & 5.79 & 2.96 & 0.175 & 44 & 151 \\
\hline \multirow{2}{*}{ S7 Red Fantasy } & $0-20$ & 5.87 & 2.96 & 0.171 & 43 & 111 \\
\hline & $20-40$ & 5.89 & 2.90 & 0.173 & 49 & 111 \\
\hline \multirow{2}{*}{ S8 Levantina } & $0-20$ & 5.74 & 2.90 & 0.170 & 50 & 135 \\
\hline & $20-40$ & 5.81 & 2.90 & 0.171 & 55 & 139 \\
\hline \multirow{2}{*}{ S9 Bellarosa } & $0-20$ & 5.53 & 3.20 & 0.181 & 40 & 135 \\
\hline & $20-40$ & 5.52 & 3.14 & 0.183 & 46 & 137 \\
\hline \multirow{2}{*}{ S10 Luna Rosa } & $0-20$ & 5.64 & 2.36 & 0.142 & 37 & 265 \\
\hline & $20-40$ & 5.80 & 2.33 & 0.150 & 33 & 179 \\
\hline
\end{tabular}

Following analysis of the soil samples taken at SC SOLFARM SRL, on a 20 ha potato cultivated area, it can be noted that the soil reaction at a depth of $0-20 \mathrm{~cm}$ falls within the range 5.44-6.04, and 


\section{Current Trends in Natural Sciences}

Vol. 10, Issue 19, pp. 121-128, 2021

https://doi.org/10.47068/ctns.2021.v10i19.016

Current Trends in Natural Sciences (on-line)

at a depth of 20-40 $\mathrm{cm}$ the $\mathrm{pH}$ value falls within the range 5.52-6.14, which represents, according to the soil reaction classes (ICPA Methodology,1987) a moderately acidic to lightly acidic reaction (Figure 2).

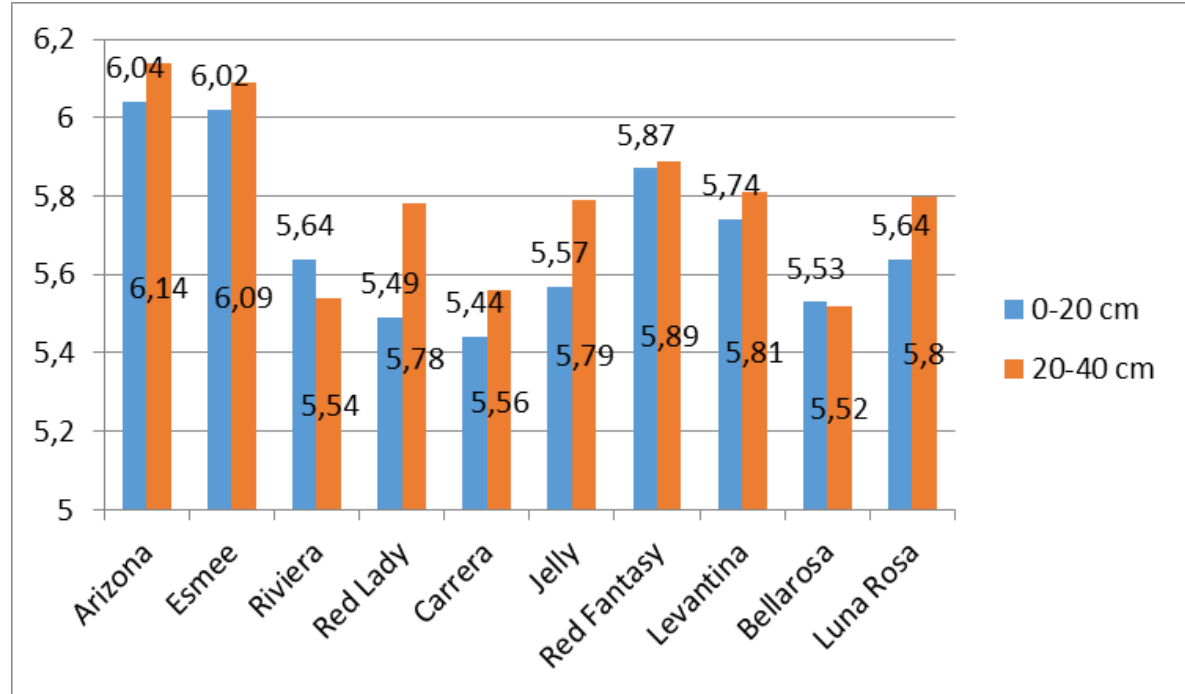

Figure 2. pH variation in the samples taken

The potato can be grown on almost any type of soil, except saline and alkaline soils. The 5.2-6.4 pH range is considered ideal for potato cultivation (FAO,2016).

The organic mater content (humus) in the soil foils within the limits of a medium to good supply ( 2.33 - 3.14) (Figure 3). The soil nitrogen supply was calculated based on its positive correlation with the humus content and the base saturation in the tilled soil layer. The soils analysed herein have a medium nitrogen supply $(0.170<$ IN <0.203) (Figure 4.)

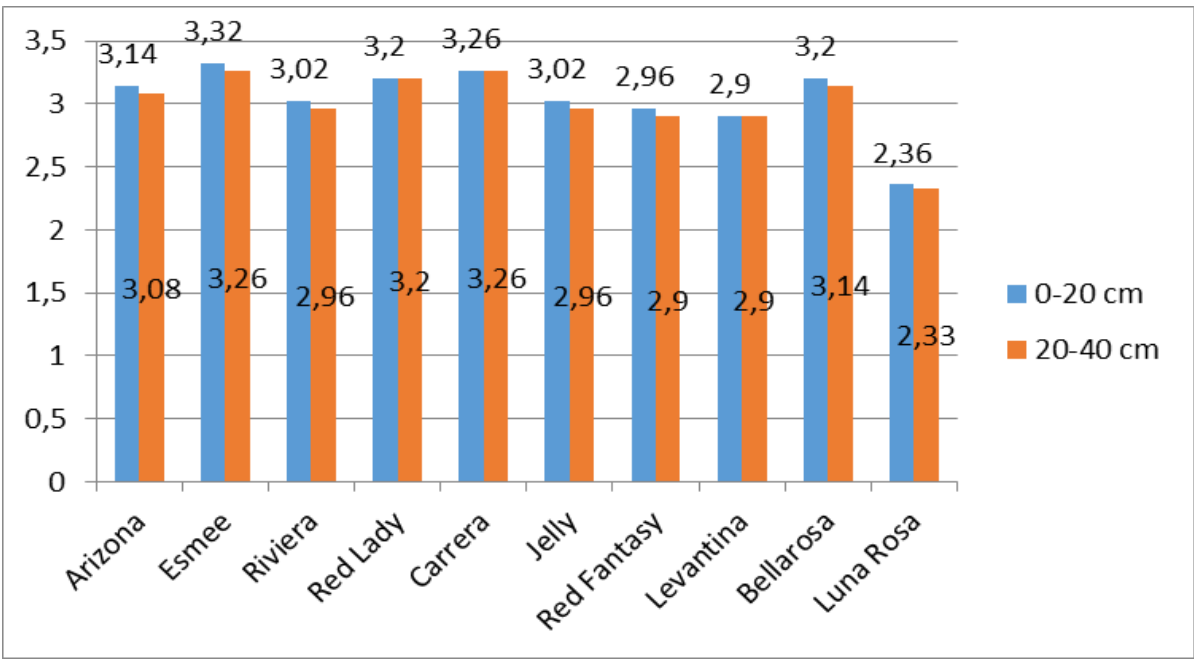

Figure 3. The lots' humus content 


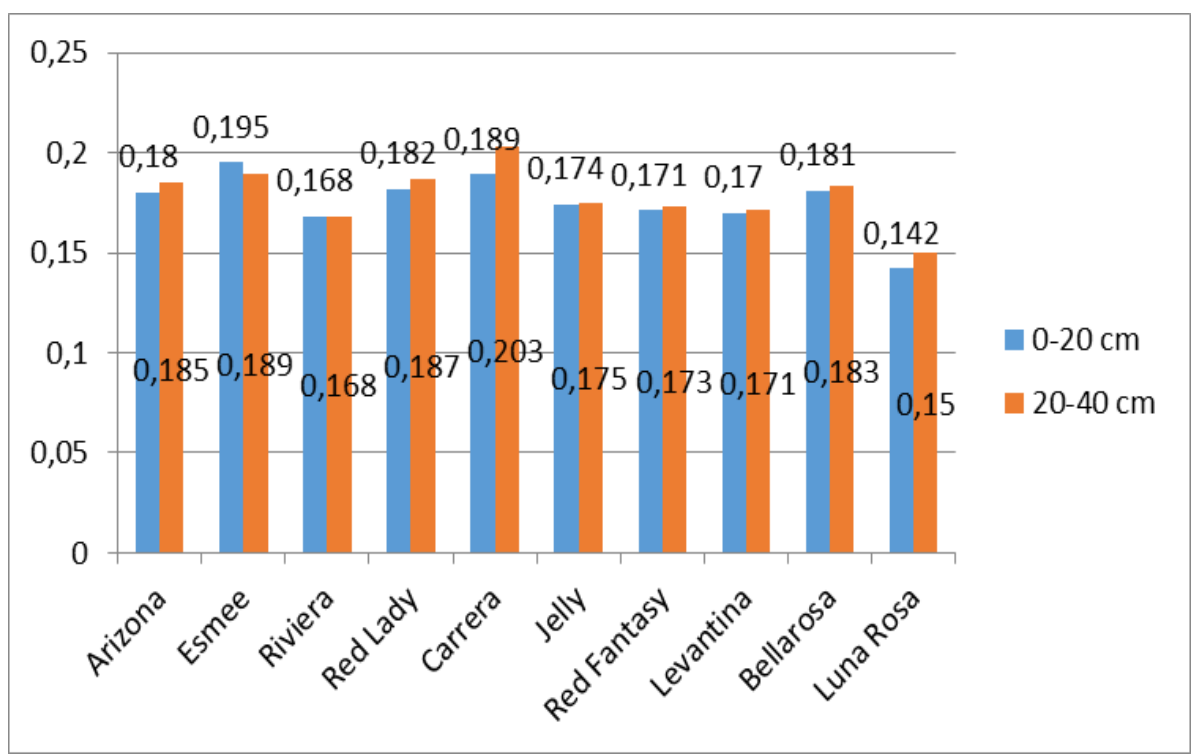

Figure 4. The lots' nitrogen supply

The potato is particularly sensitive to a constant intake of nitrogen-based fertilisers, although it requires a proper supply of nitrogen for increased yields, for a production of large size tubers with minimum internal-external tuber defects, an excessive intake of nitrogen has its own negative effect (LeMonte at al., 2009).

As regards the easily soluble phosphate content, determined by soil analysis, it represents the main factor that makes a difference in the phosphate fertiliser dose, i.e. it grows or decreases proportionally to the increase in the content of mobile phosphates in the tilled layer of the soil. As regards the nutritional supply, the soil's phosphorus supply is considered good to very good in both cases $(0-20 \mathrm{~cm}, 20-40 \mathrm{~cm})\left(37<\mathrm{P}_{\mathrm{AL}}<83\right)$. The inverse proportionality between the technical dose of phosphate fertilisers and the mobile phosphate content in the soil allows the accurate determination of the fertiliser dose on the lot under agrochemical analysis.

The phosphorus contributes to the development of the root system and the balance of the unfavourable effect of excessive nitrogen. Furthermore, it influences the increased resistance of the stalks, it stimulates the number of tubers in a hole, having an uniform uptake throughout the vegetative period (Mosaic, 2016).

As regards the soil's potassium supply, seen in Figure 5, we note a very good supply ( $111 \mathrm{ppm}<$ $\mathrm{K}_{\mathrm{AL}}<294$ ), however for high production levels, as in intensive crop farming, the application of potassium-based fertilisers is required by the high consumption of potassium and in order to balance the NPK ratio. 

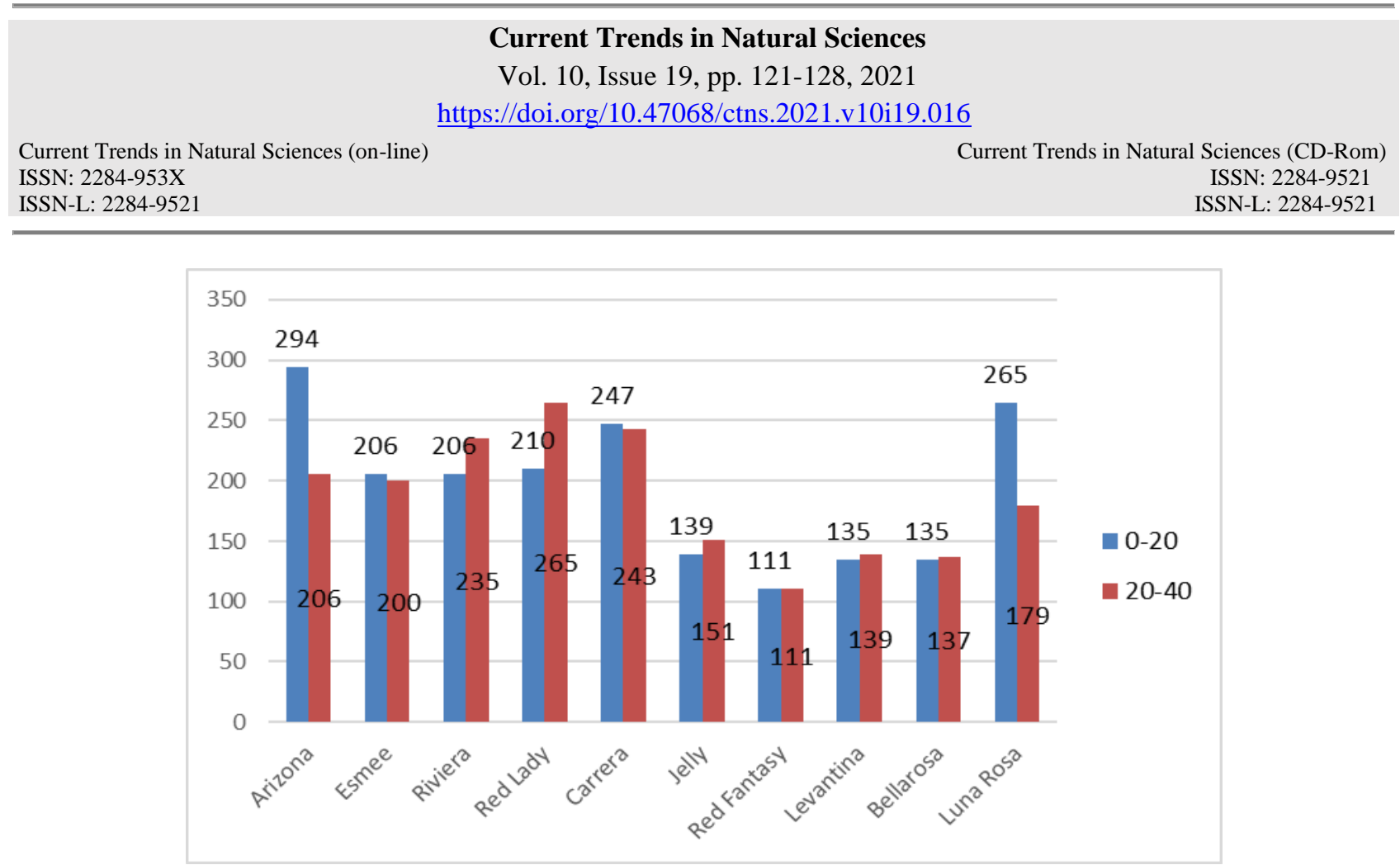

Figure 5. The lots' potassium supply

Potato plants absorb large quantities of potassium throughout the growing season and are known as a potassium preferring crop (Kelling et al. 2002; Blagoeva et al., 2004).

Potassium plays an extremely important part in potato nutrition, both in the development of the foliar system and in the production and quality of the tubers, being a photosynthesis stimulant frequently used in extra-early and early crops, and contributing to the quick growth of the tubers at the minimum harvest size (Roman, 2012).

The analysis of the main agrochemical indices on these fertilisation lots, shown in Table 1, shows that 7 lots have a moderately acidic soil reaction, which is lightly acidic on only 3 lots, where the Arizona, Esmee and Red Fantasy grow. The soil's nitrogen supply is poor on most of the lots, and a single variety (Carrera) records a medium level at a depth of 20-40 cm. As regards the soil's phosphate supply, there is just one case of medium supply, for the Luna Rosa variety, the same as for potassium in the Red Fantasy variety, the others have a good and very good supply.

This synthesis shows that the following aspects must be taken into consideration when preparing the fertilisation plan:

- on areas where the soil has moderate acidity but poor nitrogen supply, the nitrogen fertilisation must be carried out using larger doses, only with mineral fertilisers with reduced acidity, with the exception of the Red Fantasy, Esmee and Arizona varieties

- seeing as the soil's phosphorus supply is good and very good on most of the lots, phosphorusbased fertilisers will be used moderately, in lower doses

- the good and very good potassium supply on almost all the lots requires reduced doses of this type of fertiliser. 


\begin{tabular}{|c|c|}
\hline \multicolumn{2}{|c|}{$\begin{array}{c}\text { Current Trends in Natural Sciences } \\
\text { Vol. 10, Issue 19, pp. 121-128, } 2021 \\
\text { https://doi.org/10.47068/ctns.2021.v10i19.016 }\end{array}$} \\
\hline $\begin{array}{l}\text { Current Trends in Natural Sciences (on-line) } \\
\text { ISSN: 2284-953X } \\
\text { ISSN-L: 2284-9521 }\end{array}$ & $\begin{array}{l}\text { Current Trends in Natural Sciences (CD-Rom) } \\
\text { ISSN: 2284-9521 } \\
\text { ISSN-L: 2284-9521 }\end{array}$ \\
\hline
\end{tabular}

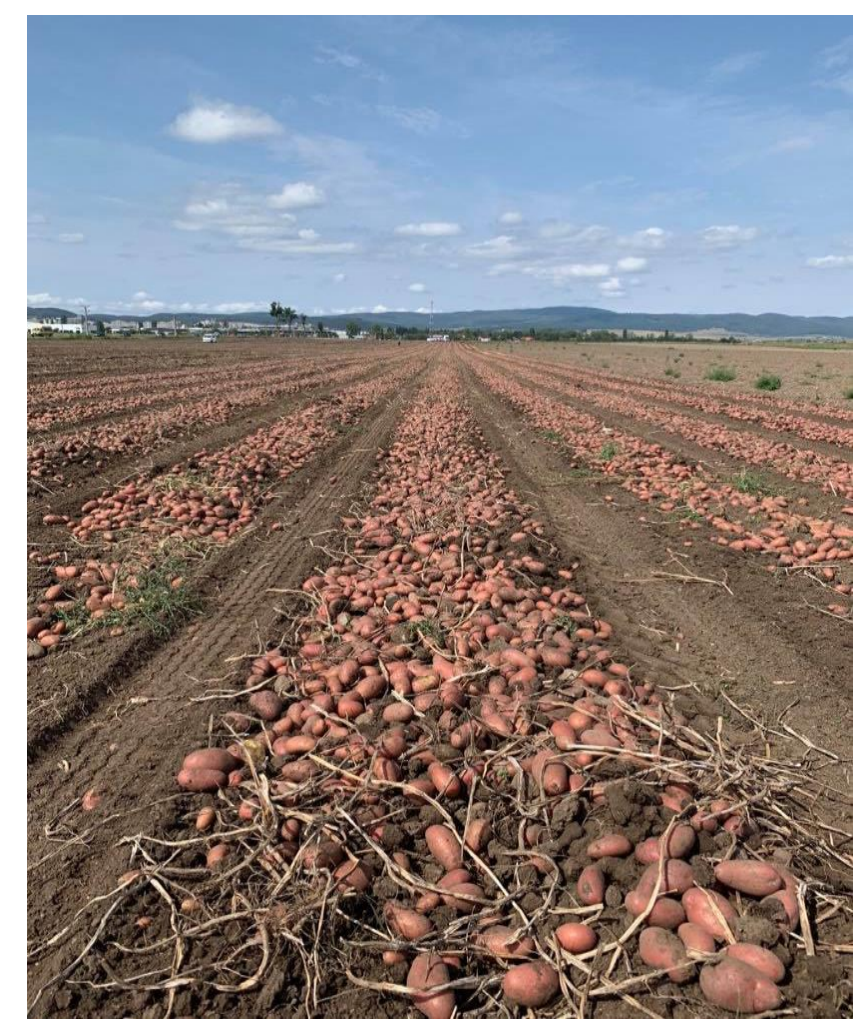

Figure 6. Potato variety Red Fantasy

\section{CONCLUSIONS}

1. The potato is a staple crop of uppermost economic and social importance for the agriculture of the Covasna county, first of all because of the ecological conditions that are more favourable to this crop and less favourable to others, and secondly as a result of the yield that it can provide compared to other crops.

2. Because of its particular soil fertility requirements, potato cultivation can become economic only on soils with good and very good nutrient supply, uniformly fertilised with the all base nutrients (NPK)

3. As regards the soil's phosphate supply, it can be noted that most of the lots have good and very good results. This synthesis shows that most lots don't have any issues regarding phosphorus fertilisation.

4. We must take into consideration the fact that almost all the land has good and very good potassium supply, which means that potassium fertilisation can be carried out using very small doses, leading to a decrease in the cost of fertilisers.

5. Limiting the acidification and defertilisation of the soil on these lots will be achieved by using ammonium-nitrate and calcium carbonate fertilisers. To ensure the uniformity of the application of fertilisers through mechanised dispersion, the fertilisers and amendments will be ground and immediately applied.

6. We believe that the results initiated by SOLFARM SRL in order to streamline potato fertilisation according to the planned yield will lead to higher and more efficient yields. 


\section{Current Trends in Natural Sciences}

Vol. 10, Issue 19, pp. 121-128, 2021

https://doi.org/10.47068/ctns.2021.v10i19.016

Current Trends in Natural Sciences (on-line)

ISSN: 2284-953X

Current Trends in Natural Sciences (CD-Rom)

ISSN: 2284-9521

ISSN-L: 2284-9521

ISSN-L: 2284-9521

\section{REFERENCES}

Agajie, T., K. Wachira, M. Gebre, G. Wolde, L. Berga and N. Demeke (2007). Adoption and impact of potato production technologies in selected districts of Oromiya and Amhara Regions of Ethiopia. Ethiopian Institute of Agricultural Research, Research Report.

Andre, C.M., Legay, S., Iammarino, C., Ziebel, J., Guignard, C., Larondelle, Y., Hausman, J.F., Evers, D., Miranda, L.M. (2014) The potato in the human diet: a complex matrix with potential health benefits. Potato Res 57, 201214. https://doi.org/10.1007/s11540-015-9287-3

Blagoeva, V., Iliev, E., Nikolova, E. (2004). Potatoes - cultivation, diseases and pests, and storage. Publisher „Enjovche” Sofia. 105 p.

Drewnowski, A., Rehm, C.D. (2013) Vegetable cost metrics show that potatoes and beans provide most nutrients per penny. PLoS One 8:e63277. https://doi.org/10.1371/journal.pone.0063277

Ekin, Z. (2011) Some analytical quality characteristics for evaluating the utilization and consumption of potato (Solanum tuberosum L.) tubers. Afr J Biotechnol 10, 6001-6010.

Izmirlioglu, G., Demirci, A. (2015) Enhanced bio-ethanol production from industrial potato waste by statistical medium optimization. Int J Mol Sci 16, 24490-24505. https://doi.org/10.3390/ijms161024490

Jagatee, S., Behera, S., Dash, P.K., Sahoo, S., Mohanty, R.C. (2015) Bioprospecting starchy feedstocks for bioethanol production: a future perspective. JMRR 3, 24-42

Kelling, K., Panique, E., Speth, P., Stevenson, W. (2002). Effect of Potassium Rate Source \& Application Timing on Potato Yield \& Quality. Presented at the Idaho Potato Conference, January 23.

King, J.C., Slavin, J.L. (2013) White potatoes, human health, and dietary guidance. Adv Nutr 4, 393S-401S. https://doi.org/10.3945/an.112.003525

LeMonte, J.L., T.W. Taysom, B.G. Hopkins, V.D. Jolley and B.L. Webb, 2009. Residual soil nitrate and potato yield with polymer coated urea. Western Nutr. Manage. Conf., 8, 77-81.

Mosaic. (2016). Essential role of phosphorus in plants.

Nesbitt, J. E., and Adl, S. M. (2014). Differences in soil quality indicators between organic and sustainably managed potato fields in Eastern Canada. Ecol. Indic. 37, 119-130. doi: 10.1016/j.ecolind.2013.10.002

Roman, Gh. V., Morar, G., Robu, T., Ștefan, M., Tabără, V., Axinte, M., Borcean, I., Cernea, S. (2012) Phytotechnics. Technical, medicinal and aromatic plants. University Publishing House, Bucharest

*** http://www.fao.org/potato-2016/en/potato/cultivation.html 